\title{
Os discursos de ódio nas eleições presidenciais de 2014 no Brasil
} Hate speeches at the 2014 presidential elections in Brazil

\author{
Regis Duarte, Karinne \\ Universidade Federal de Goiás (UFG) \\ karinneregis@yahoo.com.br \\ Fernandes Júnior, Antônio \\ Universidade Federal de Goiás (UFG) \\ tonyfer@uol.com.br
}

Forma de citar este artículo:

Regis Duarte, K. y Fernandes Júnior, A. (2019). “Os discursos de ódio nas eleições presidenciais de 2014 no Brasil", RAEIC, Revista de la Asociación Española de Investigación de la Comunicación, vol. 6, núm. 12, 166-188.

\section{Resumo:}

Esta pesquisa destina-se a analisar os discursos de ódio produzidos em torno dos protestos sobre as eleições presidenciais de 2014, no Brasil, e a dinâmica dos processos de subjetividade envolvidos. O material de análise é composto por recortes de notícias que veiculam discursos de ódio sobre as manifestações dos eleitores de direita e de esquerda, neste cenário. Para a seleção dos trechos das reportagens, utilizamos como critério os discursos de ódio veiculados pelas matérias. Como orientação teórica, utilizam-se os estudos de Michel Foucault e aciona-se, em especial, o conceito de 
dispositivo, noção que possibilita compreender os discursos de ódio como engrenagens do dispositivo de violência, a partir de uma complexa e heterogênea rede de elementos, e que permite descrever as regularidades discursivas presentes nos enunciados analisados. A análise recai sobre a investigação da regularidade dos discursos de ódio, e o funcionamento do dispositivo sobre o cenário político brasileiro. Os resultados obtidos apontam para a produção de verdades que concorrem para se legitimar determinados posicionamentos político-partidários, no país. Assim, investiga-se a atualização do dispositivo no intuito de se responder a uma demanda do nosso tempo: como solucionar as crises enfrentadas no Brasil.

Palavras-chave: discursos de ódio, dispositivo, eleições presidenciais brasieiras, mídia.

\section{Abstract:}

This research aims to analyze the hate speech produced around the protests in the Brazilian presidential elections in 2014 and the dynamics of the processes of subjectivity involved. The material analysis is composed of clippings that convey hate speech about right-left political positions voters in this context. To choose the excerpts from the reports, we use as criteria the hate speech conveyed by the media. As a theoretical guide, the studies of Michel Foucault are used, and the concept of dispositive is particularly useful, a notion that pretend to understand the hate speech as gears of the dispositive of violence as a complex and heterogeneous network of elements and that allows to describe the discursive regularities present in the clippings analyzed. The analysis is based on the investigation of the regularity of hate speech, and the functioning of the dispositive on the Brazilian political scene. The results obtained point to the production of truths that compete to legitimize certain political positions in the country. Thus, we investigate the updating of the dispositive in order to respond to a demand of our time: how to solve the crises in Brazil.

Keywords: hate speech, dispositive, Brazilian presidential elections, media. 


\section{INTRODUÇÃO}

O objetivo deste trabalho é analisar a produção dos discursos de ódio produzidos em torno dos protestos ocorridos em torno das eleições presidenciais, no Brasil, em 2014. Para alcançarmos tal objetivo, as questões que se colocam são: qual é a regularidade discursiva identificada na veiculação dos discursos de ódio? Quais são os elementos (apagamentos, novidades, repaginações, repetições) que podemos verificar na constituição desses discursos? Como as linhas que compõem o dispositivo de violência são delineadas, através dos discursos de ódio ${ }^{1}$

Os discursos de ódio são uma das engrenagens do que definimos como dispositivo de violência. ${ }^{2}$ O dispositivo de violência, acionado pelos discursos de ódio e por práticas institucionais, medeia e produz relações do sujeito consigo mesmo de forma que o indivíduo-eleitor possa se reconhecer como sujeito de visibilidade e de enunciação nas/por essas práticas discursivas e não discursivas.

Pensar a violência enquanto dispositivo pressupõe analisar a rede de elementos que 0 integram, em sua multiplicidade heterogênea, capturando, momentaneamente, as linhas que o constituem, e que se inscrevem em poderes e saberes que concorrem para a objetivação/subjetivação do sujeito.

É necessário inserir a complexidade e a singularidade dos protestos no interior de processos que são históricos, econômicos, políticos, culturais, e os efeitos de verdade produzidos pelos discursos de ódio, nesse cenário, na fabricação de comportamentos, na legitimação de ideias, regras e valores que têm dado o tom de um "conflito armado"; um campo de guerra entre os apoiadores do governo do Partido dos Trabalhadores (PT), de um lado, e os que protestam contra ele, de outro.

\footnotetext{
${ }^{1}$ Esse trabalho é parte de pesquisa de doutoramento intitulada "O dispositivo de violência a partir dos discursos de ódio em torno das manifestações brasileiras", realizada no Programa de Pós-graduação em Psicologia, da Pontifícia Universidade Católica de Minas Gerais - PUC-Minas, entre os anos de 2014 e 2017.

2 Acionar o conceito de dispositivo de violência é uma tentativa de ruptura, de transgressão em direção a novos modos de subjetivação e de objetivação do sujeito; é a possibilidade de deslocamento de leituras que alocam a violência em algum lugar, - na sociedade ou no interior das pessoas, - para compreender que a violência tem sua própria história e, portanto, o que nos parece evidente é fabricado em determinada época e pode ser, assim, problematizado.
} 
Entendemos como discursos de ódio os discursos cujos conteúdos manifestam quaisquer formas de discriminação, preconceito e criminalização - social, econômica, política, cultural, de gênero, de orientação sexual, de etnia, de raça, de religião produzindo estereótipos, incitando práticas de violência e/ou justificando o ódio e a intolerância (Duarte, 2018, p. 86).

O discurso de ódio apresenta, como elemento central, conteúdos que desqualificam, humilham e inferiorizam pessoas e grupos sociais, ou seja, os efeitos produzidos pelos discursos de ódio são a discriminação das pessoas, produzindo a marginalização e o sofrimento ético-político "que surge da situação de ser tratado como inferior, subalterno, sem valor, apêndice inútil da sociedade" (Sawaia, 1999, p. 56), aprofundando as graves condições de desigualdade social vivenciadas pelos brasileiros.

Os discursos de ódio são uma verdade de seu tempo, em que a singularidade do discurso e as práticas não discursivas conectam-se estrategicamente no/pelo dispositivo, em determinadas circunstâncias, historicamente datadas. Toma-se dispositivo como: a) uma rede de elementos heterogêneos, discursivos e não discursivos, e a natureza da relação que se estabelece entre tais elementos; b) uma resposta a uma urgência de seu tempo; e c) função estratégia em um dado momento. (Foucault, 1979, p. 246)

O dispositivo de violência vai se configurando em consonância com elementos sociohistóricos na tentativa de se responder a uma demanda do nosso tempo, a saber: quais seriam as alternativas possíveis para o enfrentamento da suposta crise vivenciada pelos brasileiros.

Então, analisaremos os discursos de ódio como um dos elementos que constitui o dispositivo de violência, através de fragmentos de reportagens veiculadas pela grande mídia brasileira sobre os protestos em torno das eleições presidenciais de 2014.

\section{MARCO TEÓRICO}

Esta Os discursos, segundo Michel Foucault (2008), constituem subjetividades, estabelecem relações, conformam ações ao construírem, concretamente, a realidade 
em determinado espaço/tempo e, nesse sentido, há uma positividade no ato de dizer. Segundo García Fanlo (2011, p. 7):

Todo dispositivo tem uma genealogia e uma historicidade que explica seus regimes de aparição, reprodução, funcionamento e crise que resultará una nova configuração da rede de saber/poder e, consequentemente, novas formas de experiências (García Fanlo, 2011, p. 7, tradução livre).

Para Paixão (2016, p. 20) não é somente pela linguagem que se pode dizer que algo existe, ou que esse algo é isso e não outra coisa, mas, por algo anterior à linguagem, que a envolve e a faz existir: o discurso, "mesmo as palavras: sem o discurso, seriam meros sons ou borrões de escrita sem sentido algum, pois o sentido, se é possível falar de sentido, com sentido ou sem sentido, isso se trata de um dado discursivo."

Para Fernandes (2007, p. 85), embora o discurso se materialize na língua(gem), ele não se restringe apenas a essas duas dimensões. O discurso é exterior à língua(gem) e, nesse sentido, a análise se desloca do sujeito falante para o sujeito falando, tendo a produção de sentidos como parte integrante do cotidiano desse sujeito.

Os diferentes sentidos que uma palavra assume devem ser interpretados a partir do seu contexto de produção, e dos lugares socioideológicos de onde os sujeitos falam. Ideologia é, portanto, inerente à noção de discurso, e a produção dos discursos deve ser pensada como elemento integrante da História.

Para a Psicologia Discursiva (PD) a variedade de influências e de antecedentes dificultam uma definição única de discurso e de Análise de Discurso, o que não é visto como um problema, mas como expressão da riqueza das perspectivas discursivas no campo da Psicologia, e um motor que alavanca debates permanentes. Apesar das influências de distintos marcos filosóficos, é possível identificar elementos em comum: "as diferentes aproximações estão articuladas por uma atenção compartilhada em direção à significação e em direção aos aspectos estruturantes da linguagem, e estão associadas às análises interpretativas e reflexivas" (Garay; Iñiguez; Martínez, 2005, p. 110, tradução livre). 
O foco da PD é a fala tal como é usada pelos participantes em qualquer interação social. Assim, a linguagem é concebida como prática de construção da realidade e como prática social. A linguagem, nesse sentido, constrói a realidade, e não apenas a descreve.

Em consonância com as principais premissas da Psicologia Discursiva, - que, inclusive, a distingue da Psicologia Social tradicional, - acreditamos que não há uma realidade pronta e acabada a ser descoberta, por tratar-se de uma construção em que nos engendramos como seres humanos e construímos o mundo que nos rodeia. Assim, todas as formas de conhecimento são construções historicamente datadas e culturalmente localizadas. Conhecimento e ação social são elementos inseparáveis.

Como nos explica Foucault $(1996$, p. 6) “o discurso não é simplesmente aquilo que traduz as lutas ou os sistemas de dominação, mas aquilo por que, pelo que se luta, o poder do qual nós queremos apoderar." No processo de construção discursiva sobre as eleições presidenciais brasileiras de 2014, o discurso movimenta elementos de ordem discursiva e não-discursiva e, como afirma Veyne (2009, p. 57): “o dispositivo mistura, portanto, vivamente, coisas e ideias (entre as quais as de verdade), representações, doutrinas, e até mesmo filosofias, com instituições, práticas sociais, econômicas, etc."

O dispositivo é, ele próprio, discursivo e não discursivo. Portanto, o discurso não paira sobre o dispositivo - é imanente a ele; não há dispositivo fora do discurso e essa conexão sustenta, portanto, o fazer metodológico da pesquisa. Portanto, acreditamos que a noção de dispositivo (Foucault, 1979; Deleuze, 1990) é uma inovação teóricometodológica no campo dos estudos sobre a violência. É o que veremos, a seguir.

\section{METODOLOGIA}

Pensando o dispositivo como o entrelaçamento de práticas de saber, poder e de subjetivação, Deleuze (1990, p. 2) o associa à ideia de um novelo, composto por uma multiplicidade de linhas de naturezas distintas que o atravessam em todos os sentidos, e em diagonal.

Um dispositivo é "uma máquina de fazer ver e fazer falar", que comporta quatro tipos de linhas: de visibilidade, de enunciação, de força e de subjetivação. Em cada época, há 
maneiras de sentir, de perceber e de dizer que conformam regiões de visibilidade e campos de enunciação.

As linhas de força atravessam todos os pontos do dispositivo e nos coloca em meio a elas, o tempo todo. Aqui, se destaca a dimensão de saber-poder proposta por Foucault cujas linhas, segundo Deleuze (1990, p. 3), levam as palavras e as coisas à luta incessante por sua afirmação.

Um dispositivo também é composto por linhas de subjetivação, ou seja, linhas que inventam formas de existir já que "é necessário distinguir, em todo o dispositivo, o que somos (e que não seremos mais) e aquilo que somos em devir: a parte da história e a parte do atual." (Deleuze, 1990, p. 3)

Sobre as maneiras de se estudar um dispositivo, Sargentini (2016, p. 30-31) assevera que:

(...) vários gestos são necessários, dentre eles desnaturalizar aquilo que se põe como assentado na história, fazendo emergir o acontecimento; não aquele incrustado na história tradicional, mas aquele que se dá em seu processo de acontecimentalização. (...) O conceito de dispositivo é, portanto, pautado na noção de rede, de relações estratégicas, considerando que teórica e metodologicamente auxilia-nos a reunir a dispersão dos discursos e acompanhar as práticas discursivas que de forma ramificada produzem, em um ruído silencioso e contínuo, as transformações dos discursos que circulam na sociedade (Sargentini, 2016, p. 30-31).

Aqui, a tentativa é a de se instalar nas linhas que constituem e que atravessam o dispositivo de violência, buscando capturar, através dos discursos de ódio produzidos sobre o cenário político eleitoral brasileiro, a capilaridade heterogênea de elementos que compõem essa maquinaria discursiva.

O material de análise compreende fragmentos de reportagens divulgadas pela grande mídia nacional, sobre os protestos de eleitores de direita e de esquerda, nas eleições brasileiras para presidência. Aqui, a seleção dos trechos das reportagens segue o critério 
do conteúdo de ódio veiculado pelos discursos. Os portais selecionados foram: Terra Notícias e UOL Notícias. ${ }^{3}$

Para Prado Filho e Teti (2013), o dispositivo constitui uma peça central da política moderna. Como uma maquinaria sofisticada e atualizada, o conceito-realidadedispositivo é, ao mesmo tempo, conceito e prática, objeto e método, alvo de estratégias de desmontagem e resistência que recusa a racionalidade verticalizada e hierarquizada dos "grandes saberes modernos."

O dispositivo da violência cria mecanismos e estratégias de regulação, intervenção e modificação da vida dos brasileiros, no contexto das eleições. Nesse sentido, para Agambem (2009), o dispositivo é a criação e proliferação de mecanismos da política contemporânea para controlar a conduta e as opiniões de todos os seres humanos na sociedade capitalista. Na raiz de todo dispositivo, está o desejo de felicidade e a captura e subjetivação desse desejo. Esta é, então, a potência de todo dispositivo. Todo dispositivo implica um processo de subjetivação, sem o qual o dispositivo não pode exercer sua função de governo, reduzindo-se ao exercício da mera violência.

\section{RESULTADOS}

As eleições presidenciais de 2014 acirraram a histórica polarização política entre os partidos de direita e de esquerda, comum em todos os regimes democráticos. Para Brugnago e Chaia (2015, p. 101), o Brasil se encontrava, até pouco tempo atrás, mergulhado em uma aparente apatia política, cujos efeitos podiam ser observados: a) no pouco interesse da população em participar de questões políticas; b) no centrismo ideológico entre os partidos de maior representatividade, que dispensavam as particularidades de suas ideologias políticas e trabalhavam com poucas diferenças entre eles; c) no descrédito da democracia, já que os processos de participação e inclusão eram percebidos como falhos; d) na insatisfação com o voto, que não trazia resultados claros para a população; e e) no esvaziamento das ideologias partidárias.

\footnotetext{
${ }^{3}$ A escolha por essas imprensas se justifica pelo fato de comporem as maiores referências jornalísticas do país, por suas redes de cobertura, que abrangem todos os estados brasileiros, pelo altíssimo índice de suas audiências, constituindo-se como os maiores grupos midiáticos nacionais, os maiores portais em atividade, do país, e os sites mais visitados.
} 
A campanha eleitoral de 2014 não apenas aprofunda essa polarização, mas, também, é momento em que a esquerda irá se declarar contrária ao projeto neoliberal do Partido da Social Democracia Brasileira (PSDB), e o radicalismo conservador de direita se posicionará antipartidário e antipetista.

\section{UOL NOTÍCIAS 15/11/2014 18h22 Atualizada 17/11/2014 12h06}

"Por volta das 16h30, um homem foi agredido por dois idosos, que participavam do protesto, ao andar pela Paulista com uma camiseta vermelha cuja estampa havia uma foice e um martelo estilizado. Os dois homens com cabelos grisalhos que não quiseram se identificar bateram com bandeiras do Brasil na cabeça do advogado Alexandre Simões, 33, aos gritos de "Volta pra Cuba, lá é o seu lugar". Simões, que declarou seu voto em Dilma, disse que estava voltando para casa nos arredores da Paulista, quando se deparou com o protesto.

Parte dos manifestantes que seguiam pela avenida Brigadeiro Luis Antônio, no sentido centro, xingavam moradores de prédios que penduraram bandeiras vermelhas e do PT nas janelas aos berros de "o socialismo não existe". Alguns moradores revidaram chamando-os de "direita coxinha."

A reportagem do UOL também foi hostilizada por alguns manifestantes aos gritos de "imprensa petralha."

As expressões petralha e coxinha utilizadas para classificar apoiadores do governo, e manifestantes contrários a ele, caracterizam discursos de ódio. A contração da expressão petista com a imagem dos Irmãos Petralha (os célebres ladrões criados por Walt Disney), associa a ideia de petistas à de ladrões, ou seja, transmite-se a ideia de que todo apoiador do PT é ladrão.

A referência ao popular salgadinho brasileiro, a coxinha, também é um termo depreciativo utilizado para classificar os eleitores do PSDB como conservadores, representantes de uma classe burguesa despolitizada, cujos interesses são voltados ao benefício próprio. 
A imagem do militante de esquerda é repaginada, e fabrica-se um novo personagem no campo político: o revolucionário de direita, ou coxinha. Nesse campo, as posições partidárias definirão, também, os perfis dos manifestantes de direita e de esquerda.

A grande mídia reforça as representações construídas em torno dos dois personagens, e reproduz novas edições das manifestações, nesse campo de forças. Mais uma vez, estávamos diante de uma clara divisão de classes. As linhas de visibilidade e de enunciação - o que pôde ser visto e como pôde ser dito sobre as manifestações e sobre os manifestantes - articulam diversificados elementos que se complementam e se reforçam.

Os apoiadores do PSDB atribuem a culpa da crise enfrentada pelos brasileiros a um modelo socialista defendido pelos eleitores do PT que, inclusive, devem sair do Brasil e voltarem para Cuba. Os eleitores de esquerda são vistos como brasileiros que desrespeitam as regras democráticas do jogo político

De outro lado, os eleitores do PT desqualificam as posições político-partidárias de direita, afinal, são coxinhas. Inseridos em um jogo de saber/poder sobre o cenário político, os discursos de ódio são a principal estratégia utilizada para se justificar a crise política brasileira, a falência das instituições políticas, o descrédito dos partidos e de seus representantes. Tais ideias se ampliam e se sustentam de formas distintas, nas/pelas posições político-partidárias dos manifestantes de direita ou de esquerda

\section{UOL Notícias 01/11/2014 15h26 Atualizado às $20 h 45$}

"Boa tarde, reaças", cumprimentou ao microfone o empresário Paulo Martins, que foi candidato a deputado federal pelo PSC no Paraná. "É inegável que o PT constrói uma ditadura no país", acrescentou, sob fortes aplausos do grupo, que depois seguiu em caminhada."

A caminhada foi marcada também por provocações entre simpatizantes da esquerda e da direita. Na avenida Paulista, alguns moradores de prédios da região estenderam nas janelas camisetas vermelhas e bandeira da campanha à reeleição da presidente." "Vai para Cuba", gritaram os manifestantes em 
resposta. Eles fecharam uma das faixas da avenida, onde vendedores ambulantes ofereciam camisetas dizendo "impeachment já".

É necessária a volta do militarismo. O que vocês chamam de democracia é esse governo que está aí?", criticou o investigador de polícia Sérgio Salgi, 46, que carregava cartaz com o pedido "SOS Forças Armadas".

Os manifestantes diziam que o resultado das eleições deste ano de ser a "maior fraude da história" e o PT de ser "o câncer do Brasil". "Pé na bunda dela [presidente], o Brasil não é a Venezuela", gritaram."

Em discurso, o parlamentar disse que, se seu pai fosse candidato a presidente, ele teria "fuzilado" a presidente. Segundo ele, Jair Bolsonaro será candidato em 2018 "mesmo que tenha de mudar de partido".

"Eu voto no Marcola, mas não voto na Dilma, porque pelo menos o Marcola tem palavra", disse, em referência a Marcos Willians Herbas Camacho, o Marcola, um dos chefes da faç̧ão criminosa PCC."

Articulando o ver e o dizer, estão as linhas de força, terceiro elemento do dispositivo, retificando as linhas de visibilidade e de enunciação, delineando suas formas e traçando os caminhos que serão percorridos na produção de saberes sobre a política nacional, e de que maneira tais saberes poderão manifestar sua existência.

As linhas de força nos dizem sobre a composição e a disposição estratégica das práticas discursivas, atuando na produção de novas formas de objetivação sobre as manifestações contrárias e a favor do governo. As linhas de força, para Deleuze (1990, p. 1-2), "estabelecem o vaivém entre o ver e o dizer, agem como fechas que não cessam de entrecruzar as coisas e as palavras, sem que por isso deixem de conduzir a batalha."

Entre os elementos do dispositivo, existe um tipo de jogo entre as posições que os sujeitos ocupam, as funções discursivas e as mudanças produzidas. Pode-se dizer que, os protestos, tomados como objeto das linhas de força, se tornam visíveis e enunciáveis 
pelos discursos midiáticos a partir da instauração de novas edificações de regimes de verdade.

Vejamos. Se os protestos dão visibilidade a um campo que deve ser conhecido - o cenário político do Brasil - isso se deve a práticas e a relações de poder cada vez mais perspicazes que, ao torna-lo alvo, lançam sobre ele racionalidades cada vez mais ardilosas, no sentido de solidificar estratégias de intervenção e objetivação nos e sobre os corpos e condutas dos brasileiros.

O medo vermelho, materializado como o câncer do Brasil”, intensifica a intolerância, o preconceito e a violência entre os grupos de esquerda e de direita. As ruas e as mídias sociais se transformam em um verdadeiro campo de guerra, e o Brasil ficou dividido em dois grandes blocos: de um lado, a direita conservadora representada pelo candidato do PSDB, Aécio Neves e, de outro, a esquerda tendo como representante Dilma Rousseff, do PT.

Novas racionalidades são produzidas para se justificar a ameaça petralha, e os discursos conservadores de direita se radicalizam ainda mais. "Pé na bunda dela", que deveria ser fuzilada, referindo-se à presidenta Dilma Rousseff. Não se trata apenas de censurar os militantes de esquerda, de confrontá-los em protestos nas ruas e na internet, mas, de se construir mecanismos que materializem essa ameaça, como vimos nos fragmentos das reportagens que veiculam a ideia de governo-ditadura do PT.

O PT e seus defensores tornam-se objeto de análise e, ao mesmo tempo, alvo de intervenção. Discursos historicamente produzidos sobre a esquerda são reeditados e ganham novo fôlego, como vimos nos fragmentos que fazem circular a imagem de uma esquerda comunista, cuja ideia associa-se à de usurpadores da liberdade e da democracia, como nos trechos "Vai pra Cuba" e o "Brasil não é a Venezuela."

Os distintos perfis de eleitores produzidos são efeitos temporários das tensões entre os múltiplos processos de objetivação/subjetivação promovidos e modificados pelas linhas de força que, ao capturá-los e falar sobre eles, criam distintas visibilidades sobre os sujeitos e sobre suas condutas. 
Ao olharmos para o funcionamento discursivo dos enunciados que falam sobre a situação política do país, segundo a perspectiva das linhas de força, observamos que os sujeitos que falam dos campos da mídia e da política apresentam uma regularidade em seus enunciados - o caráter criminoso dos representantes do PT e o perigo que o governo de esquerda representa à população - o que justifica, inclusive, o clamor por intervenção militar no país.

Desde as eleições de 1989, ocasião em que Lula (PT) se candidata pela primeira vez à presidência da república, tais saberes vêm sendo ardilosamente construídos pelos grupos, classes e instituições contrárias à ideologia político-partidária de esquerda, inseridos numa lógica do "nós versus eles", o que favorece análises binárias e excludentes.

Tal estratégia não é explicativa, mas, classificatória e moralizante. Para o adensamento das discussões, é necessário evidenciar os micropoderes em sua permanente relação com os macropoderes, e leituras polarizadas minam essa possibilidade.

Ao discutir a construção do discurso da crise e sua relação com o dispositivo de segurança, Souza $(2016$, p. 87) afirma que a atual crise econômica e política no país foi precedida pela construção de discursos que enfatizavam fenômenos como o recuo do crescimento econômico, o desemprego e o aumento da taxa de inflação para os opositores à presidenta Dilma, durante a campanha eleitoral de 2014, com o objetivo de evitar sua reeleição.

Assim, as informações que eram divulgadas para a população brasileira acerca do cenário econômico brasileiro focavam-se em pesquisas que apresentavam índices de aumento do dólar, baixo crescimento, inflação elevada e queda da Bolsa de Valores. Tais discursos exploravam o medo de uma possível reeleição de Dilma, pelo mercado financeiro, e as consequências negativas para a população, com a suposta (e desastrosa) reeleição, aos olhos do mercado. Como o biopoder lida com a gestão da vida, alguns paradoxos produzidos parecem difíceis de serem contornados. 
A parcela de brasileiros que elege Dilma à presidência torna-se também a responsável pelo fracasso econômico do país. Se o objeto e o objetivo do biopoder é a vida, os riscos e perigos à sobrevivência da espécie devem ser eliminados e, como os perigos são imanentes à própria população, as estratégias de se eliminar o adversário petralha se justificam e se pulverizam por todas as classes sociais, inclusive, dentro das camadas mais carentes da população, maiores beneficiadas pelas políticas sociais implantadas pelo governo do PT.

O poder não está localizado nos aparelhos de Estado, nas formas jurídicas ou em uma classe dominante, mas em lugares estratégicos onde se encontram as relações de saberpoder, com suas tecnologias próprias em cada relação de forças, na vida cotidiana. $\mathrm{Na}$ contramão da evolução da etimologia da palavra, o poder, na concepção de Michel Foucault, não é nem algo que podemos tomar posse, nem um atributo que se possua ou não, mas, sim, um jogo de forças, um exercício permanente e instável.

A mídia não só veicula informações, mas é produtora de saberes e de subjetividades. As estratégias de poder, imanentes à vontade de verdade, multiplicam discursos de ódio endereçados, principalmente, aos apoiadores do governo e aos representantes do PT. A mídia faz ver que a discussão acerca do cenário político brasileiro é a reiteração dos graves problemas provocados pelo governo do PT, dos prejuízos historicamente produzidos pelos partidos de esquerda, e dos perigos da influência de uma ideologia esquerdista-comunista para o desenvolvimento progressista do país.

PORTAL TERRA 27 OUT 2014 08h31 Atualizado às 11h58

"Muitos eleitores de outras regiões do Brasil "culparam" os cidadãos dos Estados do Nordeste pelas mazelas da nação. Segundo esses internautas, a boa votação da petista no norte e no nordeste é culpa única e exclusivamente dos programas sociais."

Se eu ver um cangaceiro nordestino fdp aqui em SP eu mato", disse uma eleitora paulista, talvez se esquecendo que a cidade onde ela mora foi construída por migrantes e imigrantes de todo o mundo, incluindo os nordestinos. 
Já um eleitor carioca resolveu atacar os nordestinos com um argumento um pouco sem sentido, ainda mais em tempos de falta de água no Sudeste. "Esses nordestino (sic) fdp tem que morrer na seca mermo, povo escroto, mamando na teta do governo, tudo ignorante $f d p^{\prime \prime}$.

A vitória de Dilma Rousseff foi acompanhada da revolta dos apoiadores do PSDB, que justificavam a derrota através de discursos de ódio contra os eleitores de Dilma, especialmente, dos nordestinos, grade parcela de seu eleitorado. Vemos, mais uma vez, o país dividido em duas grandes regiões: o nordeste e o sudeste. A direita começa a discutir estratégias de se ver livre do PT. A insatisfação dos eleitores pró-Aécio, com o resultado nas urnas, provocou protestos por vários dias após as eleições, principalmente, nas mídias sociais, onde a ingerência petista é fortemente declarada.

As análises desqualificadoras sobre as políticas de governo, a intensa exploração sobre denúncias de corrupção e o envolvimento de políticos do PT materializam a 'ameaça vermelha' no imaginário social: a estreiteza de relações entre Brasil e países que se declaram de esquerda, como Venezuela, Bolívia e Cuba é vista como um perigo à democracia, pois representa uma possibilidade de golpe comunista; os programas sociais criados pelo governo do PT, como o Bolsa Família, apenas incentivam o desemprego, favorecem o aumento da taxa de natalidade (a poluição do espaço com mais pobres que são os maiores beneficiários dessas políticas), desvalorizam o mérito da classe média e média-alta, como as políticas de cotas e de financiamento de estudos nas universidades destinadas às minorias sociais que seriam as únicas "privilegiadas", e o ódio da direita se generaliza a todas as pessoas indesejáveis e imprestáveis apoiadoras do governo, e que exploram as riquezas produzidas pela classe conservadora. As riquezas do Brasil já têm dono e, portanto, devem ser privatizadas. Sobre o principal alvo da direita, e os motivos de sua indignação, Brugnago e Chaia (2015, p. 116-117) esclarecem que:

O capitalista não se sente mais explorando os pobres; ele é um trabalhador que construiu o seu patrimônio. (...) A classe branca se coloca em lugar de minoria. O PT Ihe explora; os gays vão corromper a sua família; os índios vão ficar com 
suas terras; os negros vão roubar suas vagas na faculdade; estudantes pobres do REUNI vão estudar de graça com o seu dinheiro; os cubanos vão roubar suas vagas de médicos; os pobres vão ficar com os impostos que eles trabalharam tanto para pagar; o Estado não vai Ihes dar segurança, pois para isso teria que prender pobres votantes (Brugnago e Chaia, 2015, p. 116-117).

Como afirma Souza (2016), a vitória de Dilma Rousseff, no segundo turno, não silencia as previsões de uma crise devastadora. A reação de rejeição do mercado foi imediata, mas, os motivos não estavam muito claros. Seria pelo fato de a presidenta não afagar os olhos do mercado? Ou por que outros fenômenos foram se agrupando em discurso? Em novembro e dezembro de 2014, outros discursos começam a circular, através da mídia, como, porexemplo, a crise na Petrobrás, os escândalos de corrupção encontrados pela Polícia Federal, cujo potencial superava ao caso do Mensalão. Pouco se sabia, naquele momento, a respeito da corrupção na Petrobrás, mas, como esclarece Souza (2016, p. 97), "só a colocação em discurso da possibilidade já produz a ideia de uma potencial consolidação da crise anunciada antes das eleições".

O último elemento que compõe o dispositivo é o das linhas de subjetivação, que inventam formas de ser e de existir. Assim, as formas pelas quais os indivíduos buscam reconhecer-se como sujeitos desta experiência e as dinâmicas ligadas aos processos de objetivação/subjetivação são essencialmente dinâmicas de poder, isto é, "de poder ligar o indivíduo à sua individualidade, de poder (des)marcar-lhe um estatuto e uma lei de verdade" (Marcello, 2003, p. 94)

A atualidade de um dispositivo em relação aos dispositivos anteriores é a nossa atualidade, o que somos em devir daquilo que, pouco a pouco, deixamos de ser, separando assim, em todo dispositivo, as linhas do passado recente das linhas do futuro próximo. Tal processo nos traz o novo, marca a descontinuidade em nossas existências, rompe com o transcendental e problematiza uma identidade temporal determinada no/pelo jogo das distinções. Enquanto máquina de produção de subjetividades, o dispositivo é, também, máquina de governo dos corpos. 
Além da fabricação do petralha, particularmente o do norte do Brasil, associa-se à sua identidade outros estereótipos: "cangaceiro filho da puta", "povo escroto", "mamando na teta do governo", "tudo ignorante". Observa-se a produção de subjetividades fascitóides que alimentam uma cultura da violência, da intolerância, do ódio e do preconceito na busca de se garantir espaços de liberdade. É o que afirma Fernandes Júnior (2016, p. 212):

São as práticas discursivas de um dado momento histórico que apagam, constroem, legitimam ou dão visibilidades a dados saberes construídos. Vivemos em uma sociedade em movimento, cujas constantes mudanças promovem a constituição de sujeitos que buscam se constituir nesse contexto. Mudanças que geram medo, insegurança, para citar esses exemplos, que, por correspondência, estão vinculados a um paradoxo atual: o desejo de segurança e o exercício de liberdade (Fernandes Júnior, 2016, p. 212).

Apoiadores do governo e eleitores de direita são objetivados e subjetivados pelos discursos que circulam na mídia, pelas crenças de autoridades políticas, e por toda uma variedade de práticas institucionalizadas e instituintes de normas, condutas e desejos. Além disso, o indivíduo-eleitor subjetiva-se ao se reconhecer e se identificar com esses discursos que o estigmatiza como coxinha ou petralha.

\section{CONCLUSÕES}

Para Rancière (2014, p. 50), experimentamos hoje um ódio endereçado à democracia, que se constitui de forma paradoxal: de um lado, revela-se contra uma forma de governo considerada ditatorial, autoritária ou tirânica, em cada época e, de outro, esconde uma oposição mais íntima, onde o governo democrático eficiente é aquele capaz de controlar as ameaças imanentes à própria vida democrática.

O objetivo de nossos governantes é rechaçar o sistema democrático, bem como os saberes do povo, ignorantes políticos diante dos saberes especializados dos gestores. A tentativa é, então, se livrar do povo e o objetivo é imanente à sua própria prática, como pontua Rancière (2014, p.52): “despolitizar os assuntos públicos, situá-los em lugares 
que não sejam lugares e que não deixam espaço para a invenção democrática de lugares polêmicos.

Os enunciados possuem uma dinâmica particular de retornar, de se repaginar e de permanecer o mesmo, mesmo não o sendo. Analisar a violência como objeto conceitual, através da análise dos discursos de ódio proferidos e proliferados em torno das manifestações recentes, no Brasil, requer um diagnóstico do presente que não se restringe apenas à época atual, ou seja, não se trata apenas de analisar os discursos de ódio como produção descolada dos processos de subjetivação e objetivação do sujeito.

Ao escolhermos os discursos de ódio, os produtores desses discursos (que se produzem por estes, também), se individualizam enquanto sujeitos odiosos, intolerantes, preconceituosos e violentos, e tais identidades marcam não apenas os processos de objetivação, bem como concorrem para os processos de subjetivação desses sujeitos, direcionando seus desejos, forjando estilos de vida, legitimando formas "politicamente corretas" de se manifestarem, formatando valores e crenças sobre sua existência enquanto cidadãos brasileiros.

Usar uma camiseta vermelha, hastear uma bandeira de determinado partido, ou se comportar, exprimir ideias, demonstrar interesses segundo posicionamentos ideológicos específicos, por exemplo, classifica o sujeito como defensor ou traidor e, no segundo caso, deve, inclusive, ser eliminado, combatido, assassinado, exilado.

Assim, no conjunto de fragmentos analisados, foi possível evidenciar os discursos que circulam sobre a conduta que se espera do 'ser brasileiro', padrão que legitima determinadas regras e normas sobre a forma genuína de expressarmos nossa 'brasilidade', no jogo de forças político.

O combate à corrupção se restringe ao ataque seletivo a um partido, a um manifestante, a uma classe social, a uma ideologia política. Não se promovem debates sobre maior transparência entre economia e política, não há propostas efetivas de combate a corrupção, não há discussões sobre as fontes de investimentos em campanhas 
eleitorais. O que observamos é a manipulação de uma pauta urgente com finalidades bastante claras.

A governamentalidade biopolítica aciona mecanismos violentos que passam a operar no cotidiano das pessoas. Os nordestinos devem ser separados do restante da população brasileira, podem morrer de fome (e de sede), retirando-se os benefícios das bolsas do governo, e ações que violam os direitos básicos são justificadas, por razões de sobrevivência de outros, pela garantia do crescimento do estado e de superação das crises (econômica, política, emocional, partidária).

O ódio, mais que o medo, irá alimentar o dispositivo da violência e garantir o seu funcionamento, ordenando comportamentos, alinhando discursos e legitimando ações para se superar o atual momento político.

O discurso de ódio sequestra a tão comumente conhecida identidade pacífica do povo brasileiro e marca os movimentos de resistência nos mais variados espaços. Novas subjetividades são fabricadas nesse cenário: o coxinha e o petralha. Tais figuras constituirão o terreno sobre o qual e contra o qual se deverá agir. As contracondutas, nas manifestações, se constituirão na contramão dos movimentos de resistência historicamente construídos no Brasil, adquirindo novas formas no momento atual e definindo novas modalidades de luta. Concordamos com Souza (2016, p. 123) que:

...é importante que especulemos sobre as formas de nossas ações de resistência para tentarmos antecipar o como elas são esperadas, pressupostas para compor o dispositivo e como podem ser capturadas para se tornarem condutas a serem impostas futuramente, acentuando ainda mais a eficiência do poder biopolítico. (Souza, 2016, p. 123):

O dispositivo da violência, assim como o dispositivo de segurança, insere os fenômenos - as manifestações, os discursos de ódio, a intolerância aos partidos, o medo 'vermelho', a crise econômica, por exemplo - numa série de acontecimentos prováveis, cujas reações do poder ante a esses fenômenos serão 
inseridas em um cálculo de custo, estabelecendo limites aceitáveis além dos quais não se deve ultrapassar.

Para que o dispositivo se consolide, é necessário um conjunto de mecanismos e técnicas que o façam funcionar. É o que observamos hoje, no Brasil, no atual governo de Jair Bolsonaro, que pretende combater a violência e a criminalidade através de práticas violentas, como o armamento da população, o corte de investimentos para a implementação de políticas públicas de segurança, de educação e de saúde, além da legitimação de discursos de ódio endereçados, especificamente, às minorias: pretos, mulheres, gays, pobres, para citar apenas alguns exemplos.

A emergência dos discursos de ódio, - e não de outros em seu lugar, - na atualidade, inscreve-se em jogos de verdade, legitima tipos de racionalidades, faz uso de certos mecanismos de controle/condução das pessoas, ao mesmo tempo em que atua na produção de subjetividades, ao prescrever posturas politicamente corretas, no cenário dos protestos.

Os discursos de ódio inserem-se em um conjunto heterogêneo de elementos que visam garantir, paradoxalmente, uma democracia de efeito moralizante e normalizador, fabricando figuras como as do coxinha e do petralha, e que, dependendo da posição em que essas figuras ocupam na interdiscursividade, são vistos como apátridas, como um risco à ordem e à segurança.

Os efeitos de tais discursos provocam medo, intolerância e violência, reforçando racionalidades discriminatórias. Os discursos de ódio não apenas traduzem uma indignação diante da suposta crise político-econômica enfrentada pelo país, ou denuncia esquemas de corrupção do governo. O próprio discurso sofre interdições por parte da sociedade, no intuito de se controlar efeitos indesejáveis: não se pode dizer qualquer coisa, de qualquer maneira, para qualquer um e, enredado nessa disputa por sua posse, o discurso é mecanismo de poder.

Os discursos de ódio devem ser compreendidos para além de uma forma de protesto contra um governo, um grupo, ou uma classe social. Como assinala Foucault (1995), são 
batalhas contra o "governo da individualização" cujo principal objetivo é uma forma de poder.

O discurso midiático impõe saberes, constrói regras, orienta práticas, e legitima leis sobre os posicionamentos político-partidários dos brasileiros, institucionalizando o todo como sendo a própria verdade. Sobre a relação entre saber e poder, nos aponta Veyne (2009, p. 36): “(...) encontram-se num mesmo dispositivo onde se entreajudam, sendo o poder sábio na sua área, o que confere poder a certos saberes." O discurso é imanente ao dispositivo que se arquiteta nele. O discurso de ódio é uma verdade do seu tempo, com suas singularidades e bizarrices, encarnado em determinada sociedade. A verdade é, pois, um dos componentes do dispositivo.

Torna-se necessário excluir aqueles que são imprestáveis para o desenvolvimento progressista do país. Portanto, justifica-se o descarte de pessoas que são elegíveis como um fardo insustentável para o sistema, de forma indolor e menos visível, através da retirada de direitos básicos, historicamente conquistados, da falta de assistência à saúde, à educação, à aposentadoria, por exemplo. Assim como os direitos, as pessoas são abandonadas, deixam de existir, e são reconhecíveis como humanos de segunda categoria.

Esperamos que este trabalho contribua para se construir, coletivamente, mecanismos de enfrentamento que potencialize formas mais dignas e decentes de existência, a partir de práticas de liberdade que resistam aos sequestros de nossas subjetividades. Além disso, nos possibilita pensar em subjetividade construída na relação com a cidade, com espaços, territórios que, mesmo em tempos de ódio nos permita andar amados.

\section{REFERÊNCIAS BIBLIOGRAFICAS}

Agamben, G. (2009). O que é o contemporâneo? e outros ensaios. Chapecó, SC: Argos.

Brugnano, F; Chaia; V. (2014). A nova polarização política nas eleições de 2014:

radicalização ideológica da direita no mundo contemporâneo do Facebook. Aurora revista de arte, mídia e política, 7(21), 99-129. 
Deleuze, G. O que é um dispositivo. Disponível em

http://escolanomade.org/pensadores-textos-e-videos/deleuze-gilles/o-que-e-umdispositivo. Acesso em 20 de mar. 2015.

Duarte, K. R. (2018). O dispositivo da violência a partir dos discursos de ódio em torno das manifestações brasileiras. Belo Horizonte: Pontifícia Universidade Católica de Minas Gerais. Tese de Doutorado.

Fernandes, C. A. (2007). Análise do Discurso: reflexões introdutórias. Goiânia: Trilhas Urbanas.

Fernandes Júnior, A. (2016). Discursos sobre a felicidade em práticas discursivas contemporâneas. Em: Souza, K.M; Paixão, H. P (Orgs.) Dispositivos de poder/saber em Michel Foucault: biopolítica, corpo e subjetividade. Ed. Intermeios: São Paulo.

Foucault, M. (2008). A Arqueologia do Saber. Rio de Janeiro: Forense Universitária. Foucault, M. (1979). Sobre a História da Sexualidade. Em Microfísica do poder. 10ạ. Edição. Graal.

Foucault, M. (1995). A ordem do discurso. São Paulo: EDIÇÕES LOYOLA.

García-Fanlo, L. (2011). Que és un dispositivo? Foucault, Deleuze, Agamben. A Parte Rei Revista de Filosofia, 74, 1-8.

Iñiguez, L., Garay, A. e Martínez, L. M. (2005). La perspectiva discursiva en Psicologia Social. Subjetividad y Processos Cognitivos, 7, 105-130.

Marcello, F. A. (2003). Dispositivo da maternidade: mídia e produção agonística da experiência. Porto Alegre (RS): Dissertação de Mestrado.

Prado Filho, K. e Teti, M. M. A cartografia como método para as ciências humanas esociais. Disponível em http://online.unisc.br/seer/index.php/barbaroi/article/view/2471. Acesso em 25 de março de 2015. 
Rancière, J. (2014). O ódio à democracia. Rio de Janeiro: Boitempo.

Sargentini, V. M. (2015). O Dispositivo: um aporte metodológico para o estudo do discurso. Em Souza, K.M e Paixão, H. P (Orgs.) Dispositivos de poder/saber em Michel Foucault: biopolítica, corpo e subjetividade. Ed. Intermeios: São Paulo, v.1, pp. 19-36.

SAwaia, B. B. (1999). As artimanhas da exclusão: uma análise ético-psicossocial da desigualdade. Petrópolis, RJ: Vozes.

Souza, J. (2016). A radiografia do golfe: entenda como e por que você foi enganado. Rio de Janeiro: Leya.

Veyne, P. (2009). Foucault: seu pensamento, sua pessoa. Lisboa: Edições Texto e Grafia Lda. 